\title{
SEISMIC STABILITY OF REINFORCED EARTH RETAINING WALLS A. Bracegirdle*
}

\author{
ABSTRACT: \\ This paper describes a sjmplified seismic design \\ approach proposed by the author (1) (1979), based on \\ limiting deformations. Limitations of the method are \\ outlined and results of a simple computer programme \\ presented. With further analysis, charts may be \\ developed to provide a useful design tool.
}

INTRODUCTION:

Despite intensive research efforts, notably at the University of California, there remains a need for a rational seismic design approach to Reinforced Earth. Richardson (3) (1978) proposed an unduly complex and technically dubious design method. Expressed in a more useable form by Prendergast and Ramsay (7) (1980), the method does not take advantage of the plastic deformation available in reinforced earth structures, resulting in rather conservative design.

Prediction of strip tensions in statically stable walls has proved difficult due to the influences of compaction, creep in the fill material and foundation, wall geometry and many other complicating factors. Where internal failure within the reinforced earth volume occurs, greater success has been met in predicting strip tensions. Smith and Wroth(5) (1978) found that they could predict with a reasonable degree of accuracy the failure of model walls by strip slippage but had difficulty where strip breakage occurred. A simple limit equilibrium approach was used involving a search for the critical slip surface. A similar approach is proposed by the author for seismic design proceeding on the assumption that plastic deformation is provided by slippage between the reinforcing strips and backfill material.

Under static conditions it has been found that redistribution of stress to adjacent reinforcing occurs following strip breakage at some point within the wall. Stress is distributed to strips above and below the broken strip and if failure does propogate, the failure surface is inclined steeply to the horizontal. For most wall geometries it is contained within the reinforced earth volume. However, under seismic loading the potential failure surfaces become flatter and it would be anticipated that stress would be distributed horizontally to the already highly stressed strips either side of the broken one. In this case failure would propogate very rapidly and large wall displacements could be expected during the event and in subsequent events.

* Assistant Engineer, Ministry of Works and Development, Civil Division, Wellington
Some ductility may be provided by yielding of the strips. However in view of the risk of the large displacements associated with strip breakage, it is desirable to design strips to fail by slippage if the ductile properties of reinforced earth are to be used. Slippage may be achieved in higher walls by limiting strip length near the base of the wall. Careful consideration should be given to foundation design where shorter ties are used near the base.

\section{CRITICAL ACCELERATION:}

The Critical Acceleration is the horizontal pseudo static acceleration acting uniformly over the structure to achieve limiting equilibrium. For the purpose of illustrating the principles involved, the author has considered the simplest possible configuration of ties and backfill. The results obtained may be used to investigate walls of nonuniform strip length and density. A planar slip surface is assumed, although the analysis may be performed equally well for any form of surface. The slip surface generated by yielding or slippage does not necessarily conform to the locus of peak strip tensions prior to failure and is very much dependent on the extent of the backfill behind the wall and strip density. Model tests would appear to indicate the slip surface to be planar, although the true surface is probably intermediate between a circle and alog spiral.

Assuming the slip surfaces to be planar, as shown in Figures 1 and 2 , expressions may be developed for Critical Acceleration $\left(\mathrm{K}_{C}\right)$. By writing the

equations of horizontal and vertical equilibrium of the wedge in Figure 1 , eliminating $R$ and rearranging, we obtain:-

$$
\mathrm{K}_{\mathrm{C}}=\frac{2 \cdot \sum^{\mathrm{T}} \mathrm{Tx}_{\mathrm{max}}}{\gamma \cdot \mathrm{H}^{2} \cdot \mathrm{D}_{\mathrm{h}} \cdot \tan \theta} \quad-\cot (\theta+\varnothing)
$$$$
\text { Similarly by writing the equations }
$$
of horizontal and vertical equilibrium of blocks 1 and 2 in Figure 2, eliminating $Q$ and $R$ and rearranging, we obtain an expression for the Critical Acceleration $\left(K_{C}\right)$. By further assuming that the shear strength of the fill material is fully mobilised between blocks 1 and 2 the Critical Acceleration is given by:- 


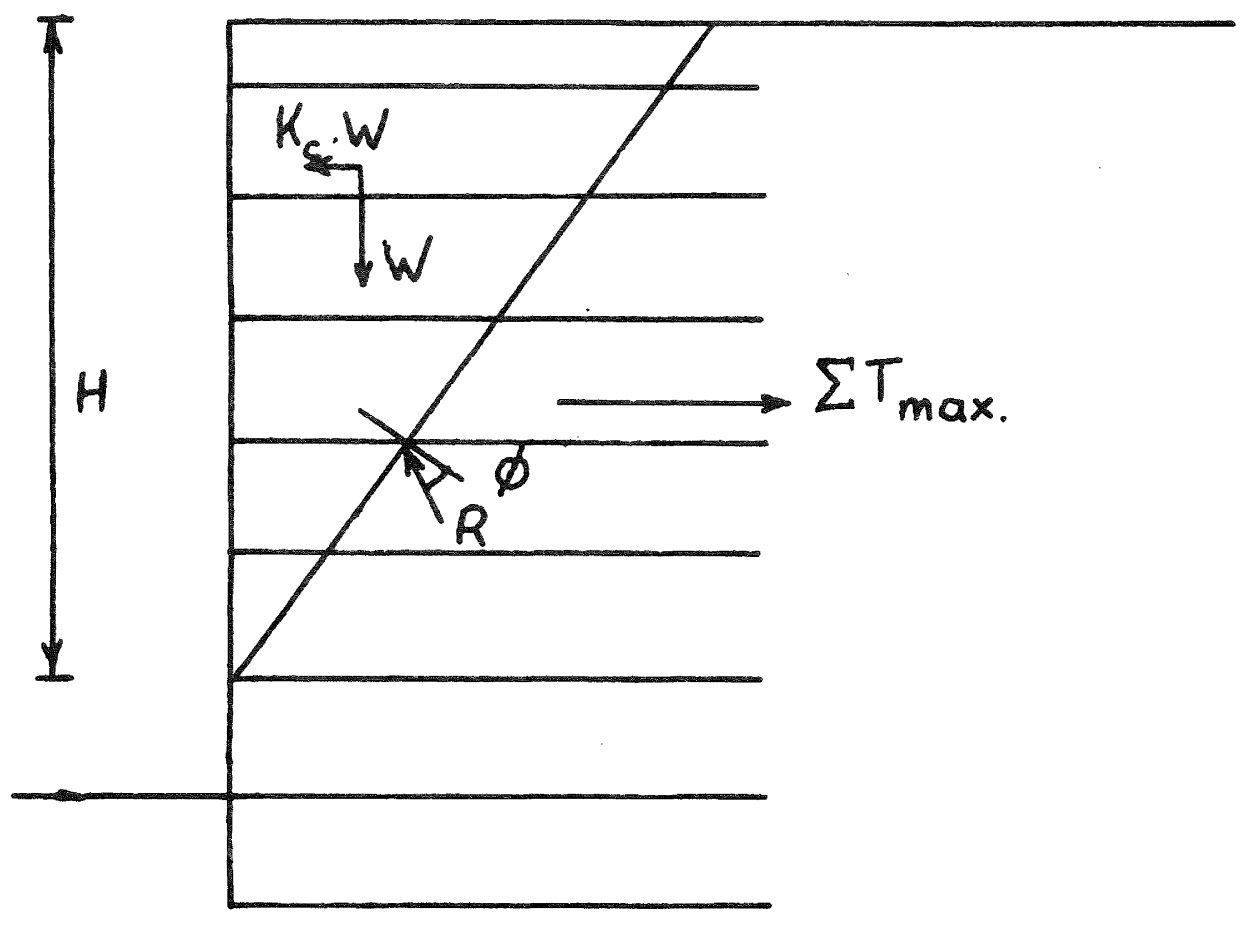

Fig. 1 - Slip surface contained.
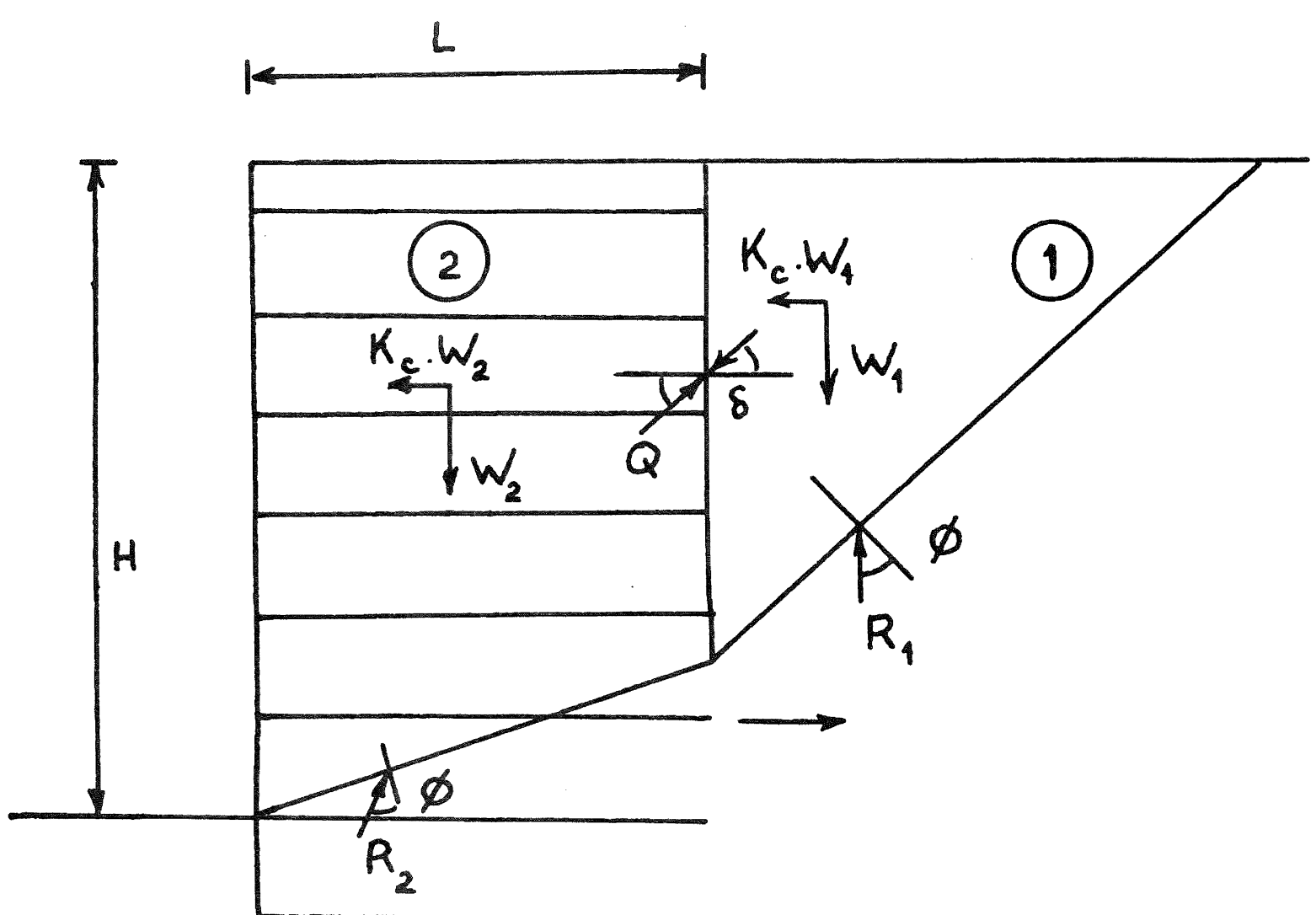

Fig. 2 - Slip surface not contained. 


$$
K_{C}=\frac{B \cdot \sin \left(2 \varnothing+\theta_{1}\right)-A \cdot \tan \theta_{1} \cdot \cos \left(\theta_{1}+\varnothing\right)}{A \cdot \sin \left(\theta_{1}+\emptyset\right) \cdot \tan \theta_{1}+C \cdot \sin \left(\theta_{1}+2 \varnothing\right)}
$$

$$
\text { where } \begin{aligned}
A= & \frac{1}{2} \cdot \gamma \cdot D_{h} \cdot\left(H-L \cdot \cot \theta_{2}\right)^{2} \\
B= & \cos \left(\theta_{2}+\phi\right)\left(\sum{ }^{T} \max _{\bullet} \cdot\right. \\
& \left.\quad \tan \left(\theta_{2}+\phi\right)-W_{2}\right) / \sin \left(\theta_{2}+2 \varnothing\right) \\
C= & W_{2} \cdot \sin \left(\theta_{2}+\phi\right) / \sin \left(2 \phi+\theta_{2}\right)
\end{aligned}
$$

After some slippage however it would be expected that the strips would become re-orientated with the slip surface. Similar equations for the re-orientated strips may be developed forming a lower bound for the Critical Acceleration. The lower bound of Critical Acceleration will provide a conservative estimate of displacement.

Where the slip surface is contained it is possible to express $\sum \mathrm{T}_{\max }$ as a series and differentiate to find the surface yielding the lowest critical acceleration. Similarly, differentiation of equation (2) may be carried out to find the critical angle $\theta_{2}$. In practice however it is found that a computer search for the critical surface is more reliable.

Programming this task is relatively simple and the output of such a program is plotted in figure 3. Each mechanism is checked in the programe for the possibility of yielding of the strips. The conditions under which strip yielding would take place have been plotted in figure 3. The possibility of failure at the bolted connection at the face has not been considered and requires further investigation. In order to safely design a Reinforced Earth Wall on this basis, checks would have to be made using the highest and lowest expected values of the internal angle of friction. The highest expected value would be used to check against strip yielding and the lowest to calculate displacements. It is reasonable to assume that the angle of friction does not deviate significantly from the static value during shaking. Experimental evidence would appear to indicate a slight increase if anything. In the formulation of figure 3 the soil/strip friction angle was considered constant, independent of wall height and equal to the internal angle of friction of the soil.

For most wall geometries and friction angles it is found that the slip surface passes out through the rear of the reinforced earth volume. The angle $\theta$ increases with wall height, length of ties and internal angle of friction. Typically it lies between $65^{\circ}$ and $85^{\circ}$. The angle of the slip surface in the material behind the reinforced earth volume is found to be given approximately by:-

$\theta=\pi / 4+1.5 \tan ^{-1} \mathrm{~K}_{\mathrm{c}}-\phi / 2$ (radians)
The influence of varying the material properties of the soil behind the reinforced earth wall may be easily examined. Where walls are built against rock higher values of critical acceleration are obtained reflecting the reduction in the volume of the slipmass. As would be expected the Critical Acceleration is independent of value taken for density of the reinforced earth fill.

\section{DISPLACEMENT CALCULATION:}

Displacements are determined using the Newmark(2) (1965) sliding block. approach assuming no amplifisation of ground motion in the wall. As discussed by the author(1) (1979), significant amplification of the motion is unlikely even where the fundamental period of the wall approaches the spectral peak of the ground motion.

In figure 4, critical acceleration has been plotted against displacement calculated using the equivalent pulse analogy developed by Sarma (4) (1976). The equivalent pulse forms an upper bound to the displacements of a sliding block subjected to a range of actual time histories. Peak base accelerations for zones $A, B$ and $C$ for a 150 year return period event as defined by the New Zealand National Society of Earthquake Engineering discussion group (ref No. 6) have been used. This in turn corresponds to a structure with a design life of 100 years with a probability of $50 \%$ of exceedence.

\section{COMMENT:}

Displacement due to extension of the strips has been ignored and in order to ensure that a conservative estimate of displacement is made this should be considered, particularly for higher structures.

The maximum acceleration to which the slipmass is subjected is the Critical Acceleration. For the majority of structures it will be found that the critical surface passes through the toe of the wall. By making assumptions as to the location of the 'inter-wedge' force $Q$, the magnitude and location of $\mathrm{R}_{2}$ may be found. Adopting a Meyerhof pressure distribution, the possibility of foundation failure may be examined.

Using the lowest probable value of the internal angle of friction, strip lengths may be reduced until the Critical Acceleration is zero. At this point the structure will be close to failure under static conditions. The extra length of the adopted strip controls displacement during a seismic event and provides an additional factor of safety against slippage. By adopting an empirical estimate of the locus of peak tie tensions it may be assured that strip breakage within the Reinforced Earth volume is unlikely. this condition is satisfied, no further internal static design is required.

Although this approach is extremely crude and at present lacks experimental 


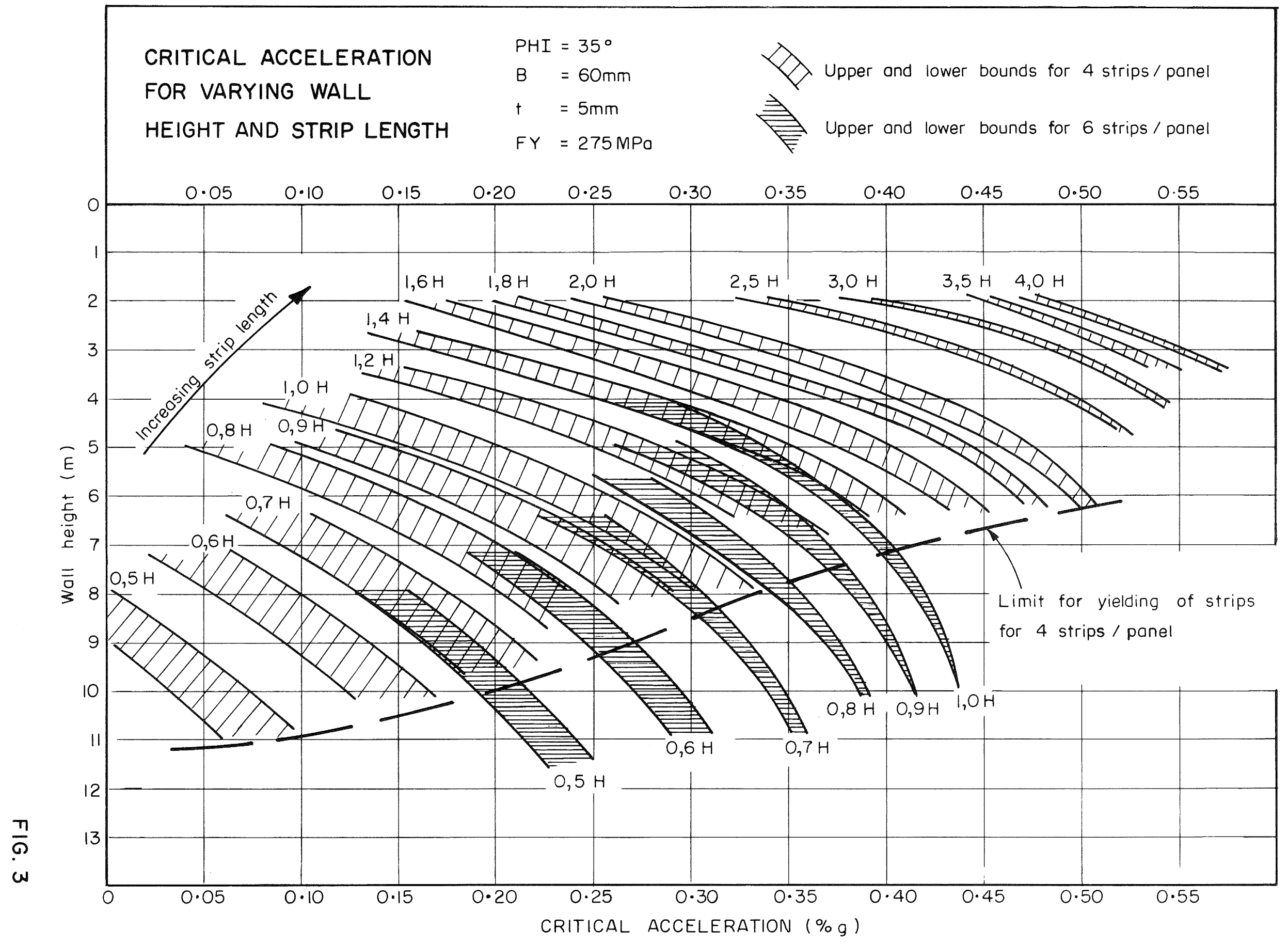




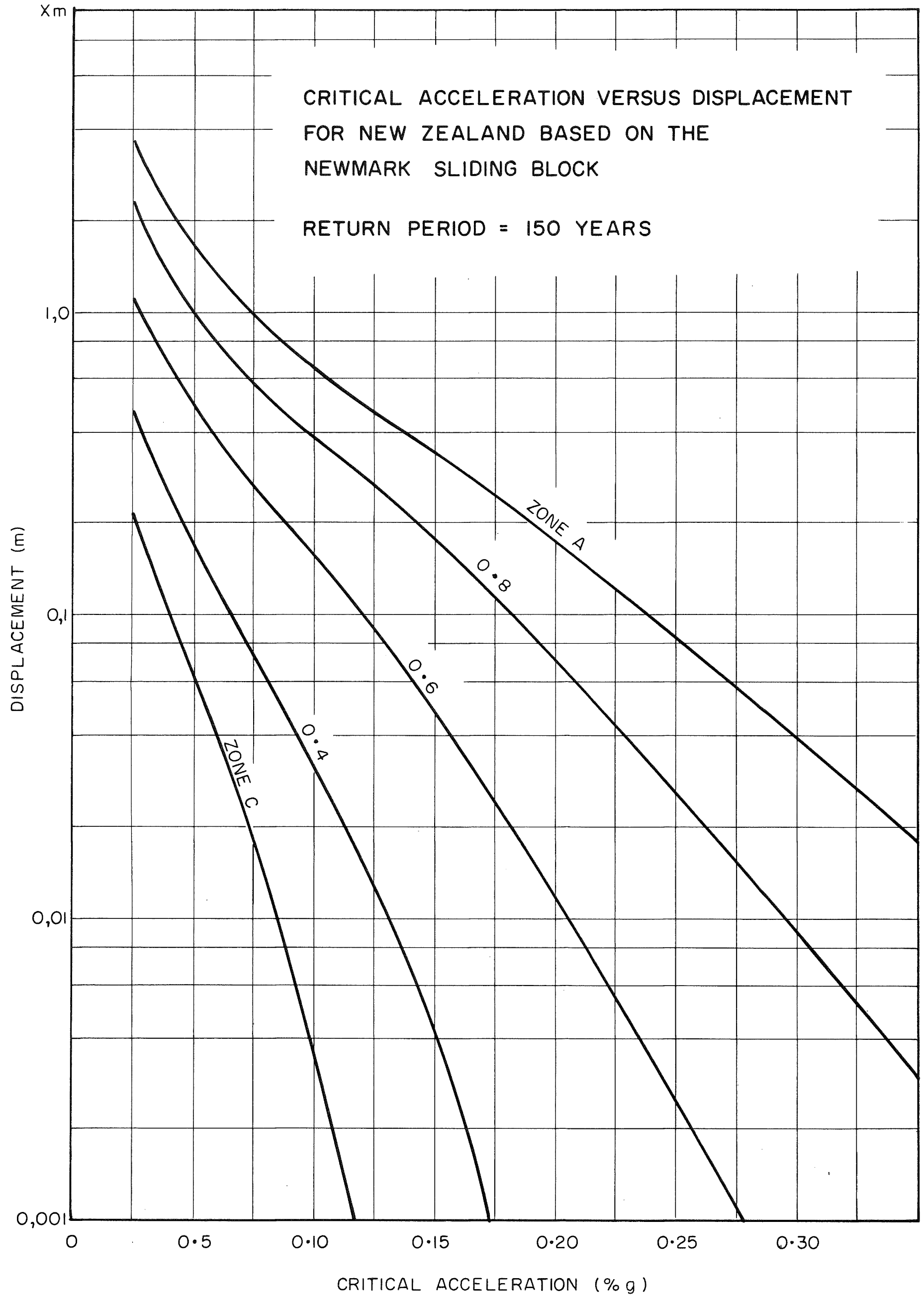

FIG. 4 
ver $i$ fication, it is believed to be conservative. Using the type of chart shown in figure 3 , the Critical Acceleration may be plotted over the full depth of the wall. Provided the foundation conditions are amenable to shortened strip lengths, yielding of the structure may be used to provide a most economic design for larger structures. However, it is often found that the length of the lower strips is determined by bearing capacity. Alternatively, slippage may be attained by thickening and reducing the width of the strips.

If yielding by slippage cannot be guaranteed, given the present "state of the art" knowledge, strips should be designed to withstand inertia forces based in the full peak base acceleration.

\section{DESIGN EXAMPLE:}

No surcharge

Wall height $=10 \mathrm{~m}$

Allowable displacement $=3 \%$ wall height (ref No. 6) say $100 \mathrm{~mm}$ in extension of ties, $200 \mathrm{~mm}$ in slippage

Location : Zone A

$\varnothing=35^{\circ}$ (Assume uniform throughout wall)

$D_{h}=750 \mathrm{~mm}$ a 4 strips/panel, $375 \mathrm{~mm}$ e 6 strips/panel

$F_{y}=275 \mathrm{MPa}$, Strip $60 \mathrm{~mm}$ wide $\times 5 \mathrm{~mm}$ thick

From figure $4, \mathrm{~K}_{\mathrm{C}} \geqslant 0.19 \% \mathrm{~g}$

Try 6 strips/panel of length $5 \mathrm{~m}$

Go to 4 strips/panel of length $7 \mathrm{~m}$ at $5.4 \mathrm{~m}$ depth

Check for breakage in lowest strip above wall base assuming locus of peak strip tensions inclined at 1:l near the base of the wall and $\sigma=\gamma \mathrm{H}$

Max tension possible $=2 . B \cdot \gamma \cdot \tan \varnothing$. $\left(L-D_{v}\right) \cdot\left(H-D_{v}\right)$

$$
=66 \mathrm{kN} \quad \mathrm{OK}
$$

$\mathrm{w}_{1}=220 \mathrm{kN}$

$\mathrm{w}_{2}=143 \mathrm{kN}$

$Q=\frac{W \cdot\left(K_{c} \cdot \sin \left(\theta_{1}+\phi\right)+\cos \left(\theta_{1}+\phi\right)\right.}{\sin \left(2 \phi+\theta_{1}\right)}$ $=84.4 \mathrm{kN}$

$R_{2}=\frac{W_{2}+Q \cdot \sin \varnothing}{\sin \left(\theta_{2}+\varnothing\right)}$

Taking moments about the toe and using a Meyerhof pressure distribution we find that the bearing pressure at the base of the wall is approximately $1,000 \mathrm{kPa}$.

By increasing tie length to $7 \mathrm{~m}$ at the base of the wall, a reduction in bearing pressure of $40 \%$ is achieved despite the increase in critical acceleration. However in order to avoid the possibility of strip breakage, narrower and thicker strips would have to be used.

\section{ACKNOWLEDGEMENT:}

The work reported was carried out with the support of the Ministry of Works and Development.

\section{NOTATION:}

B = Breadth of reinforcing

$\mathrm{D}_{\mathrm{h}}=$ Horizontal spacing of strips

$\mathrm{D}_{\mathrm{V}} \quad=\quad$ Vertical spacing of strips

$\mathrm{F}_{\mathrm{y}}=$ Yield stress of strips

$\mathrm{H}=$ Height of wall

$\mathrm{K}_{\mathrm{C}}=$ Critical Acceleration

Q = Inter-wedge force

$\mathrm{R}=$ Force acting on slip surface

$\sum T_{\max }=$ sum of tie tensions of ties passing through slip surface

$\mathrm{W}=$ Weight of a sliding wedge of thickness $D_{h}$.

$\gamma=$ specific weight of the fill material

$\sigma=$ Vertical effective stress

\section{REFERENCES :}

1. Bracegirdle A. (1979) "Reinforced Earth Walls: Static and Dynamic Considerations". MSc dissertation. Imperial College of Science and Technology.

2. Newmark N.M. (1965) "Effects of Earthquakes on Dams and Embankments 5 th Rankine Lecture. 17th February 1965. Geo-technique 15 No. 2 p. 139.

3. Richardson G.N. (1978) "Earthquake Resistant Reinforced Earth Walls" Symposium on Reinforced Earth. American Soc. of Civil Engineers pp $664-684$.

4. Sarma S.K. (1976) "Response and Stability of Earth Dams during Strong Earthquakes" Report prepared for US Army Procurement Agency (Europe) Nov. 1976.

5. Smith and Wroth (1978) "Failure of Model Reinforced Earth Walls" Symposium on Reinforced Earth. American Society of Civil Engineers, pp. $794-855$. 


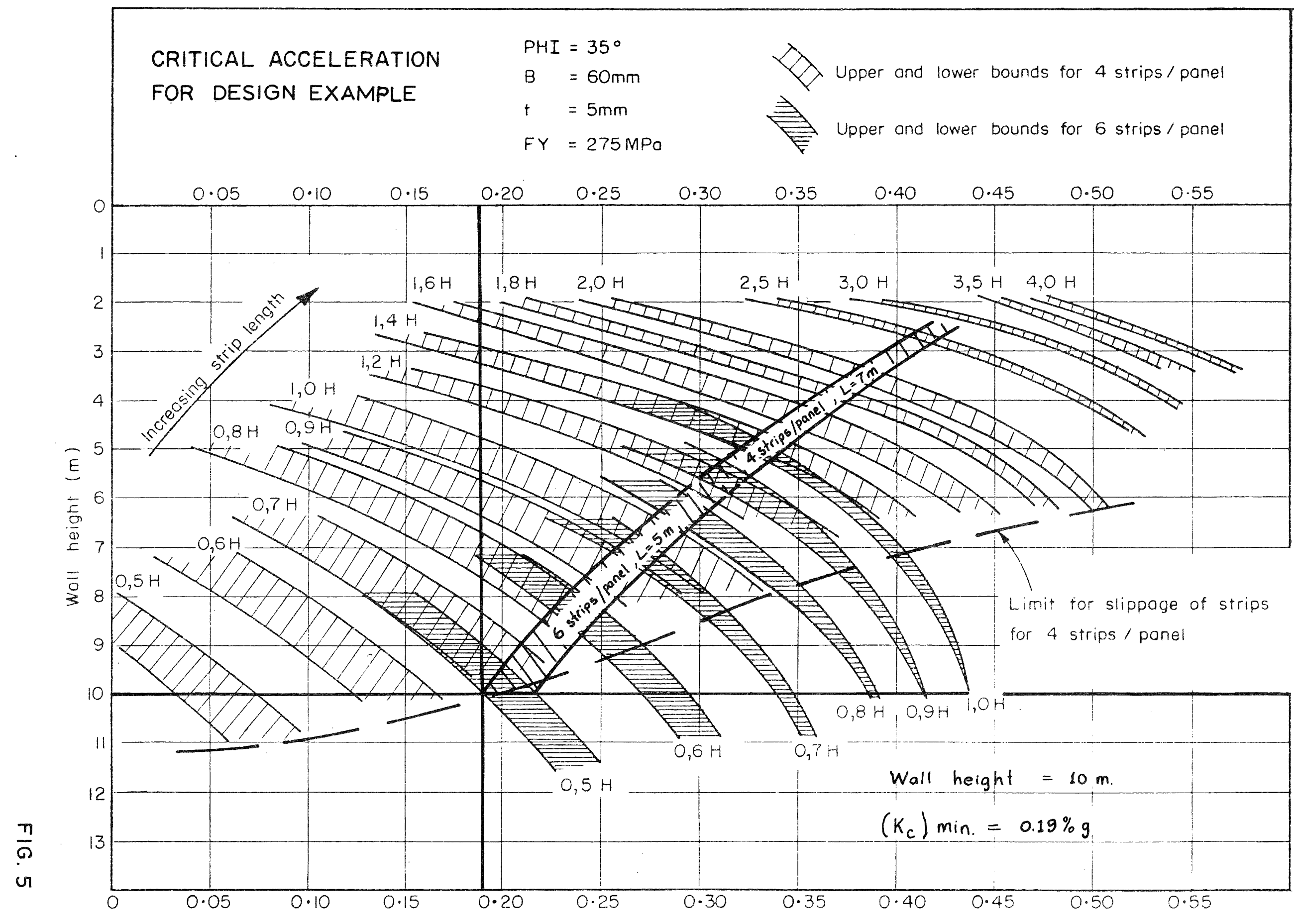


6. Papers resulting from deliberations of the Society's discussion group on the Seismic Design of Bridges, Bulletin of New Zealand National Soc. for Earthquake Engineering. Vol. 13, No. 3, september 1980.

7. Prendergast and Ramsay (1980)

"Design of Reinforced Earth for New Zealand Conditions" Third

Australia-New Zealand Conference

on Geomechanics, Vol. 1, Wellington 1980 .

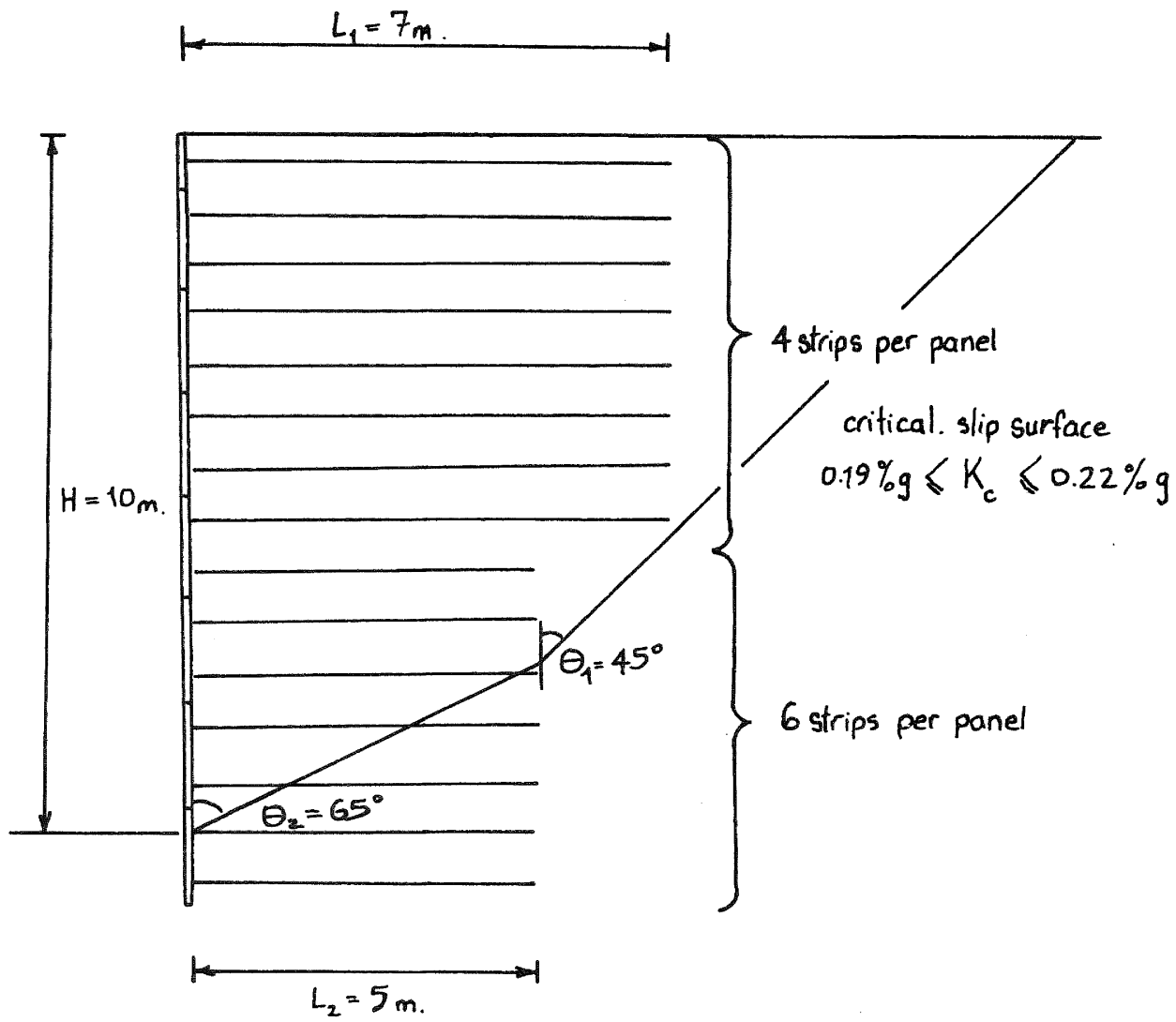

